\title{
국제개발협력과 \\ Good Governance
}

권 혁 주 / 성균관대학교 교수

개발도상국의 경제발전과 빈곤퇴치를 위하여 올바른 국정관리(Good Governance)의 중요성 이 UNDP와 세계은행을 중심으로 강조되고 있 으며, 국제개발협력 분야에서 활동하는 다양한 정책당사자들(policy stake-holders)도 이에 대한 중요성에 동조하고 있다. 그러나 올바른 국정관리 혹은 Good Governance가 무엇을 의 미하는지, 올바른 국정관리를 구축하는 것이 곧 바로 경제발전과 빈곤퇴치로 연결된다고 하는 주장이 과연 타당한 것인지 확언할 수 있는가하 는 의문을 제기할 수 있다. 그렇지 않다면 지난 몇 십년간 국제개발협력에서 부침했다가 얼마 되지 않아 사라지는 또 다른 정책유행에 불과한 것인가? 본고에서는 올바른 국정관리(Good Governance)의 이론적 배경을 검토하고 이의 정책적 시사점이 무엇인지 논의해 보기로 한다.

\section{1. 국가주도 경제발전 전략과 신자유주의의 시장주도론}

제 2 차 세계대전 이후 선진국들은 전쟁의 폐허에서 경제를 부흥하고 전쟁으로 피폐해진 국민의 삶을 윤택하게 하기 위해서는 국가가 적극적으로 나서 야 한다는 케인즈의 이론에 따라 적극적인 개입정 책을 전개했다. 케인즈의 이론에 따르면 자본주의 의 주기적인 경제공항을 극복하기 위해서는 유효 수요를 창출하는 등의 다양한 정책적 개입이 필요 하다. 케인즈 이론과 더불어 복지국가의 성장은 제 2 차 세계대전 이후 서구의 경제정책의 근간을 이 룬다. 이러한 복지국가의 성장은 국민 모두에게 시 민으로서 부끄럽지 않은 생활수준을 보장해야 하 며 이를 위해 국가는 조세정책, 사회정책 등을 통 해 적극적인 노력을 해야 한다는 사회적 합의에 기 초한 것이다(Hall 1986). 
이러한 선진국의 정책 패러다임은 새롭게 독립한 개발도상국의 발전전략에도 많은 영향을 주었으 며, 특히 동 패러다임은 UN이 개발의 10년으로 정한 1960 년대와 이어지는 1970 년대에 결정적 인 영향을 끼쳤다. 이에 따라 경제발전을 위해 국가가 적극적인 역할을 해야 한다는 국가주도형 개발전략이 많은 신생독립국에서 실시되었던 것 이다. 이와 더불어 미국과 소련의 냉전체제 하에 서 자본주의 경제체제만이 아닌 사회주의 계획경 제를 통한 경제발전 전략을 추구하는 개발도상국 들도 다수 존재하였다. 결과적으로 경제발전을 달성하기 위한 정책적 노력에서 국가의 역할이 강조되었으며, 한국과 대만과 같은 나라에서는 자본주의 경제체제를 기초로 국가 주도형 경제발 전 전략을 채택하여 눈부신 경제발전을 이루는 결과를 보여주었다.

그러나 경제발전을 위한 국가의 적극적, 주도적 역 할이 반드시 긍정적인 결과만을 창출하지는 못했 다. 아프리카의 신생독립국들은 빈번한 탈법적 정 치변화, 내전 등과 같은 역사적 격변으로 인하여 이러한 국가주도 발전전략을 꾸준히 실천하지 못 했으며, 그렇지 않은 경우라도 성공적인 결과를 창 출하는 경우는 드물었다. 국가주도형 경제전략을 추진하면서 관료들이 경제에 개입하여 국가경제보 다는 오히려 자신의 이익을 추구하는 경향을 보이 기도 하였으며 이것은 경제발전에 치명적인 장애 가 되기도 하였다.
Kruger는 관료의 경제개입의 부정적 효과를 지대 추구(rent seeking society) 이론으로 설명하였다 (Kruger 1974). 이 이론에 따르면 관료는 경제에 관한 인허가 등의 권한을 통해 특정한 경제 주체에 게 시장 우위권을 행사하도록 하여 경쟁적 시장의 가격보다 더 높은 가격으로 일종의 지대를 창출할 수 있도록 해주며, 그 일부를 공유하는 등 부정부 패를 저지르기 쉽다는 것이다. 이러한 행태는 해당 산업의 생산성을 저하하고 궁극적으로 경제발전을 막는 부정적 효과를 낳는다고 보는 Kruger의 이 론은 관료가 공동체의 목적보다는 특정한 이익, 개 인적 이해를 추구할 때 생기는 역효과를 지적하는 이론이라고 볼 수 있다.

그렇다면 이러한 부정적 효과를 막기 위해 어떠 한 방향에서 국가와 행정분야를 어떻게 개혁할 것인가? 이러한 질문은 1980 년대 경제발전의 지체현상을 보이고 있었던 아프리카, 라틴아메 리카, 남아시아의 국가들의 커다란 과제로서 부 각되었다. 여기서 두 가지 선택이 존재한다. 첫 째, 사회·경제적 이해관계로부터 국가의 중립 성을 확보하고 공무원의 전문성, 합리성을 제고 하는 방안을 생각할 수 있다. 둘째, 국가의 역할 을 원천적으로 축소하고 관료가 경제에 개입하 는 것을 대폭 축소시키는 방안이 있다. 결과적 으로 이 지역의 많은 국가들은 두 번째 방안을 선택하였는데, 세계은행(World Bank)과 국제통 화기금(IMF)이 강력한 구조조정(structural adjustment) 정책을 권고하면서 국가의 경제적 
개입 축소, 시장개방 정책 등 관료 역할을 대폭 축소시키는 행정개혁을 요구했기 때문이다 (Garba 2004). 다시 말해 경제적 중립성 확보에 실패한 개발도상국가들이 행한 처방은 공무원의 전문성, 합리성, 중립성의 제고보다는 원천적으 로 국가의 역할을 축소하여 공공부분을 축소시키 는 것이었다. 이러한 정책 패러다임의 근거에는 정부의 개입대신 시장논리에 따라 경제를 운용하 면 개인의 창의력, 기업가의 모험 등에 따라 자연 발생적 경제성장을 이룰 수 있다는 신자유주의적 논리가 자리 잡고 있다.

그러나 지난 20 년간 아프리카, 라틴 아메리카에서 시장논리에 기초하여 실시된 구조조정 정책은 경 제성장을 가져오지 못하고 오히려 경제적 쇠퇴와 사회적 희생만을 초래했다는 평가가 이루어지고 있다(Cornia et al. 1987; Deacon 2000). 한편 1980년대 이래 지속적으로 추진되어온 구조조정 으로 인해 관료제는 붕괴 직전에 이르게 되었고, 이 때문에 개발도상국가들이 경제성장, 사회발전 을 위해 어떠한 공공정책을 추진하려고 해도 이에 필요한 행정제도, 전문인력, 정책수단 등이 존재하 지 않아 정책을 제대로 집행하지 못하는 결과를 초 래했다(Kwon 2005). 이렇게 볼 때 결과론적인 평 가이지만, 1970 년대와 1980 년대에 많은 개발도상 국들이 직면했던 관료제의 문제를 시장논리에 따 라 풀기보다는 공무원의 전문성, 합리성, 경제적 중립성을 제고하는 방향에서 행정개혁을 실시했어 야 했다는 지적을 할 수 있다.

\section{Governance 이론의 대두와 공공부분이 새로운 역할}

1980 년대 이후 아프리카, 라틴 아메리카의 개발도 상국에서 강력하게 실시되었던 시장중심 경제발전 논리에 따른 구조조정이 커다란 성과 없이 실패로 귀결되자, 경제발전에서 국가 행정의 중요성에 대 한 인식이 새롭게 대두되기 시작했다. 예를 들어 Gough와 Wood는 Insecurity and Welfare Regime 제하의 최근 연구에서 개발도상국의 발전 에 가장 큰 장애는 체계적인 국가제도와 효율적인 노동시장의 부재에 있다고 지적하고 있다 (Gough and Wood 2004: 15). 경제발전의 원동력이 되는 노동시장이 원활히 작동하지 않고, 국가는 경제발 전을 위한 정책을 수행하기 보다는 소수의 엘리트 의 이익에 봉사하는 수단으로 이용되고 있다는 것 이다. 이러한 장애요인을 극복하기 위해서는 일차 적으로 효과적으로 작동하는 국가조직 및 경제제 도를 구축하는 것이 필요하다. 이러한 제도 구축이 체계적으로 마련된다면 정부관료, 기업, 노동자, 농민 등이 효율적으로 경제행위를 수행할 수 있게 된다.

신자유주의 이론에 따른 구조조정 정책을 추구하 였던 세계은행도 더 이상 경제발전을 시장기제에 맡기면 자연발생적으로 경제성장이 이루어 질 것 이라는 주장을 하지 않고 있다. 앞에서 지적한 것 처럼 국가 행정의 투명성, 합리성을 제고하고 경제 활동에 필요한 다양한 제도적 기제를 구비하고 이 
들이 원활히 활동할 수 있도록 해야 한다는 데 의 견을 같이 하고 있다. 잘 정비된 Governance의 확 립, 혹은 국가행정 및 경제제도를 확립해야 한다는 정책적 동조를 하고 있는 것이다. 그러나 세계은행 은 국가행정의 확립, 혹은 국가의 정책적 개입의 필요성 등과 같은 용어 보다는 Governance라는 용어를 선호하고 있다. 이것은 세계은행의 이념적 편향을 보여주는 단면이라 할 수 있다.

그러나 단순히 제도가 구비되었다고 해서 성공적 인 경제성장이 이루어진다고 가정할 수는 없다. 이를 위해 국정관리가 올바른 모습으로 진행되어 야 할 것이다(UNDP 1995). 이러한 논리에서 보 면 거버넌스는 국가행정 및 법체계와 그 운영 시 스템을 의미하는 것으로 굿 거버넌스 혹은 올바른 국정관리는 이러한 제도적 체계와 운영이 올바르 게 이루어 운영되는 것을 의미한다. 올바른 국정 관리에는 정책투명성(accountability), 책임성 (responsibility), 신뢰 등의 의미가 내포되어 있다. 국제개발 협력 분야의 중요 국제기구들의 굿 거버 넌스의 개념들도 이 같은 의미가 내포되어 있는 것 으로 다음과 같은 원칙들을 제시하고 있다.

It "...encompasses the role of public authorities in establishing the environment in which economic operators function and in determining the distribution of benefits as well as the relationship between the ruler and the ruled." - OECD
It is "...among other things participatory, transparent and accountable. It is also effective and equitable. And it promotes the rule of law." - UNDP

It is “... epitomized by predictable, open and enlightened policy making; a bureaucracy imbued with a professional ethos; an executive arm of government accountable for its actions; and a strong civil society participating in public affairs; and all behaving under the rule of law." - World Bank

이 같이 다양한 국제기구들이 주장하는 Good Governance 개념은 약간 씩 차이가 있으나 중요 한 면에서 몇 가지 공통점을 갖고 있는데 이를 간 단히 요약하면 다음과 같은 원칙들이 부각된다. Good Governance를 하기 위해서는 첫째, 투명성 (transparency)이 요구된다. 거버넌스에 참여하는 행위자는 다양한 입장과 이해를 갖는 공적 - 사적 행위자들이기 때문에 이들 간의 상호작용에 투명 성이 확보되면, 국가정책, 기업행위는 안정적이고 신뢰할 수 있기 때문이다(CIDA 1997). 둘째, 결정 된 공공정책을 수행한 것에 대해 정책투명성 (accountability)이 확보되어야 바람직한 거버넌스 가 이루어 질 수 있다. 이러한 정책투명성은 두 가 지 단계로 이루어진다. 먼저 정책의 목표를 달성하 기 위해 집행된 결과에 대해 공식적으로 설명 (account)하는 과정과 그 결과에 책임을 지는 
(responsible) 과정이다(UNDP 1995). 셋째, 거버 넌스 발전이론은 특정한 행위자만을 발전의 주체 로 보지 않고, 다양한 공적 - 사적 행위자의 참여가 발전에 필수적이라고 본다. 참여성의 확대를 통해 경제발전을 위한 사회적 공감대를 확보하고 다양 한 의견이 정책결정과 집행에서 수렴되면, 정책의 정당성 확보와 효과적인 정책집행이 가능하게 되 고 사회적 갈등을 최소화할 수 있다. 넷째, 사회, 경제정책이 목표로 하는 결과를 효과적으로 달성 하기 위해 사회의 역량을 제고시키는 노력이 필요 하다. 이를 위해 개인들의 역량개발(capability building), 기업의 연구개발(innovation), 공공부 분의 지속적인 개혁(public sector reform) 등이
요구된다. 다섯째, 경제, 사회의 발전이 사회의 성 원과 지역 사이에 고르게 나누어지도록 형평성도 강조해야 한다. 특히 사회적 약자의 보호와, 시장 경제 활동에서 낙오되거나 어려움을 겪고 있는 사 람들에 대한 사회복지 정책이 구비되어야 한다. 아 래의 〈그림 1〉는 전술한 Good Governance의 사 회적 원칙들을 제시하고 이에 상응하는 구체적 제 도들을 예시하고 있다.

이와 같은 제도적인 측면과 더불어 정책행위자의 측면에서 Good Governance 이론이 제시하는 발 전론의 중요한 특징은 국가와 기업, 노동자 모두를 경제발전에 중요한 행위자로 설정한다는 점이다.

〈그림 1〉 Good Gorvenance 의 원칙과 상응제도

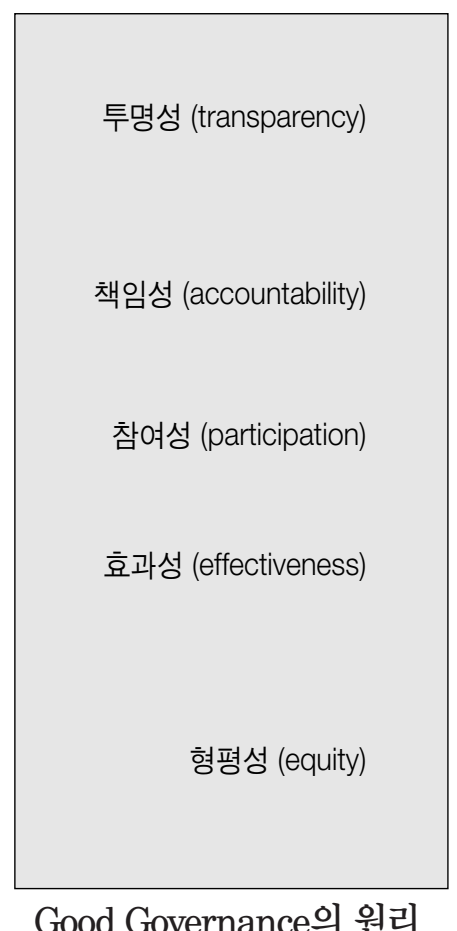

Good Governance의 원리

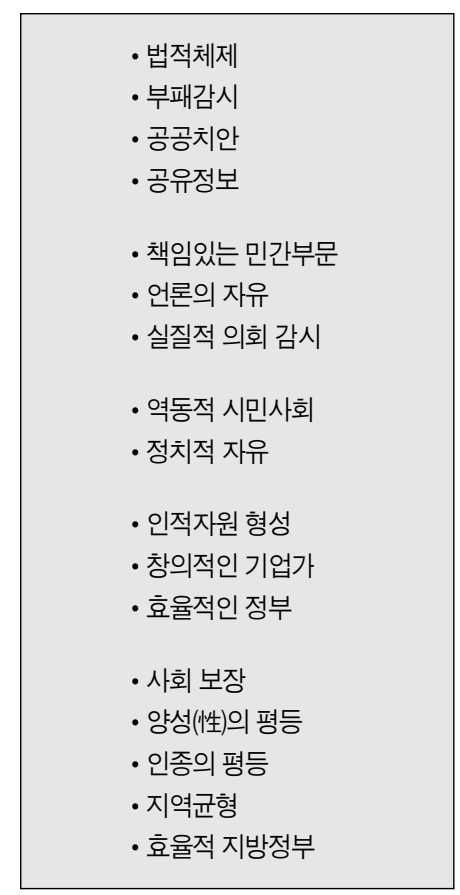

Good Governance의 내용 
뿐만 아니라 사회의 다양한 입장과 전문성을 표현 하는 시민단체도 중요한 행위자로 설정하고 있다. 이러한 다양한 행위자들이 국가운영과 시장 활동 에 필요한 다양한 제도들을 효과적으로 운영하는 데 참여하고 서로의 경제적 이해를 조정하고 타협 한다는 것이다. 이러한 Good Governance이론은 국가, 민간기업, 시민 개인들에게 공공분야에 참여 하여 어떻게 행동할 것인가 하는 다분히 규범적인 지침을 제시하고 있으며, 동시에 경제발전에 공공 부분의 역할을 적극적으로 인정하고 있다는 특징 을 보인다. 그렇다면 개발도상국들이 올바른 국정 관리를 한다면, 경제발전과 빈곤퇴치를 자연스럽 게 기대할 수 있는가?

\section{Good Governance가 경제발전을 창출 하는가?}

개발도상국에서 국가행정 체계를 구축하고, 법에 따라 질서를 세우며, 공직에 임하는 정치지도자와 관료들이 그들의 정책결정과 집행에 대해 투명하 게 국민에게 설명하고 그 결과에 대해 책임지는 것 은 그 자체로서도 가치가 있는 사회발전이라고 할 수 있다. 그러나 이러한 목적론적 이해를 넘어 올 바르게 국정을 한다면 경제발전도 함께 도모할 수 있다는 도구론적 주장도 폭넓게 제기되고 있다. 이 러한 인식은 세계은행, UNDP와 함께 천년개발목 표의 집행사항을 분석한 Sachs 보고서에서도 나 타나고 있다 (Sachs 2005).
이 보고서는 UN이 제시한 천년개발목표를 달성하 는데 많은 성과를 이루지 못한 나라들은 국정관리 (Governance)가 올바르게 이루어지지 않고 있기 때문이라고 지적하고 있다 (Sachs 2005: 15). 따 라서 천년개발목표를 달성하려면 이러한 나라들에 서 국정관리가 올바르게 이루어져야 한다는 지적 을 하고 있다. 이에 따라 Good Governance는 이 제 다자간 국제기구들이 개발도상국들을 지원하는 하나의 평가척도로 대두되게 되었다. 세계은행이 Good Governance를 평가척도로 이용한 것은 이 미 오래 전부터이다. 그런데 여기서 문제는 Good Governance를 객관적인 지표와 목록으로 표시하 면서 또 다른 경직된 차관조건으로 변모할 위험성 이 존재한다는 것이다. Governance가 올바르게 이루어지지 않는 나라에게는 차관을 제공할 때나, 기존의 부채에 대해 탕감을 해주는 것을 고려할 때 불이익을 준다는 것이다. 이러한 정책은 개발도상 국의 정부에게 국정관리를 올바르게 수행하도록 하는 경각심을 불러일으킨다는 긍정적 측면도 있 지만, 반면에 외부의 도움이 필요한 최빈국들은 대 부분은 국정관리에서도 많은 문제점을 갖고 있기 때문에 이들에게 필요한 적절한 협력정책을 구사 하는데 심각한 제약이 될 수 있다.

국제개발 협력에서 시장 주도론을 넘어 Good Governance를 강조하고 행정과 경제체제의 구축 을 위해 노력하는 것은 분명 정책적 측면에서 진일 보 한 것이다. 그러나 과연 Good Governance가 곧 바로 경제발전과 빈곤퇴치에 기여할 것인가 하 
는 것은 검증되지 않았다는 점을 지적해야 할 것이 다. 물론 정부의 관료가 타락하거나 시장에 필요한 경제제도들이 원활히 작동하지 않는다면 경제발전 을 기대하기 어려울 것이다. 이렇게 본다면 Good Governance는 필요조건이지만 충분조건이라고 단정할 수 없다는 것이다.

한편 많은 개발도상국의 경우 Good Governance 체제를 잘 구축하고 이에 따라 경제성장을 추구할 시간적, 정책적 여유가 없다. 따라서 이들은 여러 측면에서 부족한 Governance체제를 개선해 나감 과 동시에 경제발전을 추구해야 한다는 이중의 과 제에 직면하고 있다. 이 같은 맥락에서 Gore는 개 발도상국은 국제기구들이 제시하는 여러 가지 정 책적 권고사항과 그들이 각자 사정에 따라 부딪쳐 야 하는 정책적 난관을 동시에 극복해야하는 이중 적 과제를 짊어지고 있음을 지적하고 있다 (Gore 2005).
결론적으로 올바른 국정관리는 개발도상국들이 경 제발전을 위해 꼭 필요한 필요조건과 같은 성격을 갖고 있으나, 이를 단번에 구축하기란 쉬운 일이 아니며 이를 통해 반드시 경제성장과 빈곤퇴치를 할 수 있다고는 할 수 없다. 이를 위해서는 여전히 각 개발도상국 사정에 맞는 경제성장 정책, 빈곤퇴 치를 위한 다양한 사회정책들이 필요하다. 따라서 Good Governance가 개발도상국에게 만병통치약 은 아니라는 점이다. 세계은행이나 UNDP 등과 같 은 다양한 국제기구와 각국의 양자협력 기구들도 Good Governance의 중요성을 강조하고 이를 위 해 필요한 기술협력과 정책조언을 해야 하지만, 이 를 형식요건으로서 지나치게 강요해서는 안 될 것 이다. 개발협력을 연구하는 학계에서는 Good Governance와 경제성장, 빈곤퇴치를 연결하는 정 책적 대안을 지속적으로 연구하여 궁극적으로 Good Governance가 경제성장, 빈곤퇴치로 연결 될 수 있는 로드맵을 제시하여야 할 것이다. 


\section{[ 참고 문헌 ]}

CIDA. (2004). Redefining the Concept of Governance, Canadian International Development Agency.

Cornia, G., Jolly, R., and Stewart, F. (1987). Adjustment with a Human Face, Clarendon Press, Oxford.

Deacon, B. (2000). "Globalization and Social Policy." UNRISD, Geneva.

Garba, A.-G. (2004). "An Evaluation of nationalist, Keynesian and neo-liberal paradigms applied to the social development of Sub Saharan Africa." UNRISD.

Gore, C. (2004). KDGs and PRSPs: Are Poor Countries Enmeshed in a Global-Local Double Bind? in Global Social Policy vol. 4. no. 3.

Gough, I., and Wood, G. (2004). Insecurity and Welfare Regimes in Asia, Africa and Latin America; Social Policy in Development Contexts, Cambridge: Cambridge University Press.

Hall, P. (1986). Governing the Economy: The Politics of State Intervention in Britain and France, New York: Oxford University Press, Inc.

Kruger, A. (1974). "The Economics of the Rent Seeking Society." American Economic Review, 64: 291-303.

Kwon, H. J. (2005). "Social Policy and Development." Social Policy and Society, 4(4): 467-473.

Sach, J. (UN Millennium Project) (2005). Investing in Development: A practical plan to achieve the Millennium Development Goals, Washinton D.C.

UNDP. (1995). Public Sector Management, Governance and Sustainable Human Development, UNDP, New York. 